\title{
Antibacterial activity of statins: a comparative study of Atorvastatin, Simvastatin, and Rosuvastatin
}

\author{
Majed Masadeh ${ }^{1 *}$, Nizar Mhaidat ${ }^{1}$, Karem Alzoubi $^{1}$, Sayer Al-azzam ${ }^{1}$ and Ziad Alnasser ${ }^{2}$
}

\begin{abstract}
Background: Statins have several effects beyond their well-known antihyperlipidemic activity, which include immunomodulatory, antioxidative and anticoagulant effects. In this study, we have tested the possible antimicrobial activity of statins against a range of standard bacterial strains and bacterial clinical isolates.

Methods: Minimum inhibitory concentrations (MIC) values were evaluated and compared among three members of the statins drug (atorvastatin, simvastatin, and rosuvastatin).

Results: It was revealed that statins are able to induce variable degrees of antibacterial activity with atorvastatin, and simvastatin being the more potent than rosuvastatin. Methicillin-sensitive staphylococcus aureus (MSSA), methicillin-resistant staphylococcus aureus (MRSA), vancomycin-susceptible enterococci (VSE), vancomycin-resistant enterococcus (VRE), acinetobacter baumannii, staphylococcus epidermidis, and enterobacter aerogenes, were more sensitive to both atorvastatin, and simvastatin compared to rosuvastatin. On the other hand, escherichia coli, proteus mirabilis, and enterobacter cloacae were more sensitive to atorvastatin compared to both simvastatin and rosuvastatin. Furthermore, most clinical isolates were less sensitive to statins compared to their corresponding standard strains.
\end{abstract}

Conclusion: Our findings might raise the possibility of a potentially important antibacterial class effect for statins especially, atorvastatin and simvastatin.

Keywords: Antimicrobial activity, Statins, Atorvastatin, Simvastatin, Rosuvastatin

\section{Background}

Statins, also known as 3-hydroxy-3-methyl-glutaryl (HMG)-CoA reductase inhibitors, are a potent antihyperlipidemic drug group that is widely used for the treatment of hyperlipidemia. The HMG-CoA reductase is the enzyme responsible for the rate-limiting step in the cholesterol synthesis mevalonate pathway [1]. HMG-CoA inhibition results in a reduction of cholesterol synthesis and an increase in the synthesis of low-densitylipoprotein receptors. This, results in increased clearance of LDL cholesterol from the blood stream [2].

HMG-CoA reductase inhibitors are known to have effects beyond their lipid lowering effects, collectively

\footnotetext{
* Correspondence: mmmasadeh@just.edu.jo

${ }^{1}$ Faculty of Pharmacy, Jordan University of Science \& Technology, Irbid 22110, Jordan

Full list of author information is available at the end of the article
}

known as pleiotropic effects [3]. These pleiotropic effects result in improvement of endothelial function, modulation of inflammatory responses and antioxidant effects, maintenance of plaque stability, and prevention of thrombus formation [4-6]. The area of pleiotropic effects of statins is promising and several such effects are being speculated.

Statins have also been investigated for their antibacterial action. In one study of the role of statins in community acquired pneumonia, [7] statins were shown to have immunomodulatory, and antioxidative actions, and a significant effect on the concentrations systemic cytokine [812]. Several animal studies [9,13-17] and observational studies in humans [18-22] have shown that individuals treated with statins are less prone to bacterial infection and present better outcomes. The antibacterial and antiinflammatory effects of statins were investigated in a 
meta-analysis, which suggested that statin use may be associated with useful outcomes in the treatment and prevention of different infections in recipients of solid-organ transplants $[23,24]$. This study aims to further investigate the antibacterial action of statins and identify their spectrum of action.

\section{Methods}

\section{Microbial culture and growth conditions}

Antibacterial activity of statins was evaluated against different reference bacteria including E. coli ATTC 35218, Pseudomonas aeruginosa ATTC 9027, MSSA ATTC 25213, MRSA ATTC 43300, Streptococcus pneumoniae ATTC 25923, VSE ATTC 19433, VRE ATTC 51299, A. baumannii ATTC 17978, P. mirabilis ATTC 12459, Klebsiella pneumoniae ATTC 13883, Streptococcus pyogenes ATTC 19615, Haemophilus influenzae ATTC 29247, S. epidermidis ATTC 12228, E. aerogenes ATTC 29751, Citrobacter freundii ATTC 8090, E. cloacae ATTC 13047, and against clinical isolates. Eighty clinical isolates were used in this study, comprising 14 different bacterial species. They were obtained from non-duplicate clinical specimens, including ear swab, throat swab, vaginal swab, sputum, urine, and blood culture, from the Microbiology Laboratory at King Abdullah University Hospital (KAUH) in north of Jordan, between April and September of 2010.

The organisms were stored at $-70^{\circ} \mathrm{C}$ in trypticase-soy broth and 20\% glycerol (BBL Microbiology Systems, Md, USA). When ready for batch susceptibility testing, samples were thawed. To ensure purity and viability, samples were, then, passed 3 times. Minimum inhibitory concentrations (MICs) were determined in accordance with the Clinical and Laboratory Standards Institute (CLSI) [25].

Determination of minimum inhibitory concentration (MIC) The MIC was determined by serial dilution method according to the National Committee for Clinical Laboratory Standards [26]. Briefly, statins were serially diluted, and added to plates containing molten BBL Muller-Hinton Gold II agar (BBL Microbiology Systems). Thereafter, plates were slightly cooled and dried. Then, using an a steer replicator, aliquots containing about $5 \times 10^{4}$ colony forming units per drop of different bacterial strains were placed in each plate. After an 18hour incubation period at $37^{\circ} \mathrm{C}$, plates were read. MIC was defined as the lowest concentration at which no growth, a faint haze or fewer than 3 discrete colonies were detected. Plates were read in duplicate, and the highest MIC value was recorded. The breakpoints indicated in the tables of the National Committee for CLSI [26] were used to determine susceptibility and resistance.

\section{Chemicals}

Simvastatin atorvastatin and Rosuvastatin were a generous gift from Advanced Pharmaceutical Industries (Amman, Jordan). Drugs (simvastatin, atorvastatin and rosuvastatin) were dissolved in DMSO to a stock concentration of $1 \mathrm{mg} / \mathrm{ml}$, and they were used for MIC determination. All drugs were used as raw materials. DMSO was used to help in dissolving the drugs used. As DMSO is known for possessing no antibacterial activity of its own, DMSO/no statin served as a negative control.

\section{Statistics}

Analysis was performed using GraphPad Prism software (version 4.0, GraphPad software, LA jolle, CA). One-way ANOVA followed by Tukey's post-test were used to determine if there was any statistically significant difference. $P$-values $<0.05$ was considered significant.

\section{Results}

The antibacterial activity of atorvastatin, simvastatin, and rosuvastatin were investigated against 16 standard bacterial strains. Results shown in Table 1 revealed that statins are able to induce variable degrees of antibacterial activity, where atorvastatin and simvastatin are the most potent. MSSA, MRSA, VSE, VRE, A. baumannii, S. epidermidis, and $E$. aerogenes, were more sensitive to

Table 1 Minimum inhibitory concentrations (MIC; $\mu \mathrm{g} / \mathrm{mL}$ ) of different statins against standard bacteria

\begin{tabular}{|c|c|c|c|}
\hline \multirow[t]{2}{*}{ Statins } & Rosuvastatin & Atorvastatin & Simvastatin \\
\hline & $\mathrm{MIC} ; \mu \mathrm{g} / \mathrm{mL}$ & $\mathrm{MIC} ; \mu \mathrm{g} / \mathrm{mL}$ & $\mathrm{MIC} ; \mu \mathrm{g} / \mathrm{mL}$ \\
\hline E. coli ATTC 35218 & $104.17 \pm 36.08$ & $26.04 \pm 9.02^{*}$ & $52.08 \pm 18.04$ \\
\hline P. aeruginosa ATTC 9027 & $166.67 \pm 72.16$ & $83.33 \pm 36.08$ & $166.67 \pm 72.16$ \\
\hline MSSA ATTC 25213 & $208.33 \pm 72.16$ & $41.67 \pm 18.04^{*}$ & $26.04 \pm 9.02^{*}$ \\
\hline MRSA ATTC 43300 & $500 \pm 0.00$ & $83.33 \pm 36.08^{*}$ & $166.67 \pm 72.16^{*}$ \\
\hline $\begin{array}{l}\text { S. pneumoniae } \\
\text { ATTC } 25923\end{array}$ & $333.33 \pm 144.33$ & $104.17 \pm 36.08$ & $166.67 \pm 72.16$ \\
\hline VSE ATTC 19433 & $333.33 \pm 144.33$ & $83.33 \pm 36.08^{*}$ & $52.08 \pm 18.04^{*}$ \\
\hline VRE ATTC 51299 & $500 \pm 0.00$ & $166.67 \pm 72.16^{*}$ & $104.17 \pm 36.08^{*}$ \\
\hline A. baumannii ATTC 17978 & $333.33 \pm 144.33$ & $15.62 \pm 0.00^{*}$ & $104.17 \pm 36.08^{*}$ \\
\hline P. mirabilis ATTC 12459 & $250 \pm 0.00$ & $62.5 \pm 0.00^{*}$ & $166.67 \pm 72.16$ \\
\hline $\begin{array}{l}\text { K. pneumoniae } \\
\text { ATTC } 13883\end{array}$ & $333.33 \pm 144.33$ & $166.67 \pm 72.16$ & $166.67 \pm 72.16$ \\
\hline S. pyogenes ATTC 19615 & $166.67 \pm 72.16$ & $83.33 \pm 36.08$ & $62.5 \pm 0.00$ \\
\hline H. influenzae ATTC 29247 & $166.67 \pm 72.16$ & $83.33 \pm 36.084$ & $52.08 \pm 18.04$ \\
\hline S. epidermidis ATTC 12228 & $166.67 \pm 72.16$ & $20.83 \pm 9.02^{*}$ & $26.04 \pm 9.02^{*}$ \\
\hline E. aerogenes ATTC 29751 & $104.17 \pm 36.08$ & $15.62 \pm 0.00^{*}$ & $26.04 \pm 9.02^{*}$ \\
\hline C. freundii ATTC 8090 & $166.67 \pm 72.16$ & $83.33 \pm 36.08$ & $52.08 \pm 18.04$ \\
\hline E. cloacae ATTC 13047 & $166.67 \pm 72.16$ & $41.67 \pm 18.04^{*}$ & $62.5 \pm 0.00$ \\
\hline
\end{tabular}

MICs were determined using serial dilution method according to the procedures National Committee for Clinical Laboratory Standards.

* indicates significant difference from rosuvastatin group. 
both atorvastatin, and simvastatin compared to rosuvastatin $(P<0-05)$. On the other hand, E. coli, P. mirabilis, and E. cloacae were more sensitive to atorvastatin compared to both simvastatin and rosuvastatin $(P<0.05)$.

We next studied the antibacterial activity of statins against 16 clinical isolates of bacteria by measuring MIC values. Most clinical isolates were less sensitive to statins compared to their corresponding standard strains (Table 2). In addition, when compared for their antibacterial activity atorvastatin and simvastatin were significantly more potent compared to Rosuvastatin. For example, P. aeruginosa, MSSA, MRSA, S. pneumonia, VRE, A. baumannii, H. influenza, S. epidermidis, E. aerogenes, $C$. freundii, and E. cloacae were more sensitive to atorvastatin and simvastatin compared to rosuvastatin $(P$ $<0-05$, Table2). Additionally, VSE and VRE isolates were significantly more sensitive to atorvastatin compared to simvastatin $(P<0-05$, Table 2$)$.

\section{Discussion}

The emergence of drug resistance with patient's poor compliance, drugs adverse effects and the higher cost of therapy combinations, indicates a strong need for a therapy regimens with similar or higher antibiotics beneficial properties but with better adverse effects profiles. Results of the current study suggest a class effect antibacterial activity for statins, and indicate the superiority

Table 2 Minimum inhibitory concentrations (MIC; $\mu \mathrm{g} / \mathrm{mL}$ ) of different statins against different clinical isolates

\begin{tabular}{|c|c|c|c|}
\hline \multirow[t]{2}{*}{ Clinical Isolate } & Rosuvastatin & Atorvastatin & Simvastatin \\
\hline & $\mathrm{MIC} ; \mu \mathrm{g} / \mathrm{mL}$ & $M I C ; \mu g / m L$ & $\mathrm{MIC} ; \mu \mathrm{g} / \mathrm{mL}$ \\
\hline E. coli Isolates & $125.00 \pm 16.14$ & $100.00 \pm 33.75$ & $112.5 \pm 30.19$ \\
\hline$P$. aeruginosa Isolates & $291.67 \pm 39.53$ & $95.83 \pm 22.09^{*}$ & $120.83 \pm 32.27^{*}$ \\
\hline MSSA Isolates & $341.67 \pm 20.84$ & $52.08 \pm 11.04^{*}$ & $60.42 \pm 12.76^{*}$ \\
\hline MRSA Isolates & $500.00 \pm 0.00$ & $108.33 \pm 27.36^{*}$ & $116.67 \pm 30.19^{*}$ \\
\hline S. pneumoniae Isolates & $416.67 \pm 0.00$ & $229.17 \pm 60.38^{*}$ & $291.67 \pm 39.53^{*}$ \\
\hline VSE Isolates & $333.33 \pm 0.00$ & $95.83 \pm 22.09^{*}$ & $291.67 \pm 39.53 \#$ \\
\hline VRE Isolates & $500.00 \pm 0.00$ & $216.67 \pm 32.27^{*}$ & $291.67 \pm 39.53^{*} \#$ \\
\hline A. baumannii Isolates & $300.00 \pm 79.05$ & $21.87 \pm 4.94^{*}$ & $32.29 \pm 6.38^{*}$ \\
\hline P. mirabilis Isolates & $191.67 \pm 32.27$ & $127.08 \pm 25.51$ & $158.33 \pm 32.27$ \\
\hline K. pneumoniae Isolates & $258.33 \pm 64.55$ & $216.67 \pm 51.03$ & $241.67 \pm 60.38$ \\
\hline S. pyogenes Isolates & $275.00 \pm 72.17$ & $133.33 \pm 19.76$ & $145.83 \pm 32.27$ \\
\hline H. influenzae Isolates & $366.67 \pm 0.00$ & $104.17 \pm 36.08^{*}$ & $145.83 \pm 32.27^{*}$ \\
\hline S. epidermidis Isolates & $233.33 \pm 39.52$ & $19.78 \pm 4.94^{*}$ & $35.41 \pm 4.94^{*}$ \\
\hline E. aerogenes Isolates & $183.33 \pm 0.00$ & $19.78 \pm 4.94^{*}$ & $33.33 \pm 4.94^{*}$ \\
\hline C. freundii Isolates & $333.33 \pm 79.06$ & $108.33 \pm 27.36^{*}$ & $133.33 \pm 39.58^{*}$ \\
\hline E. cloacae Isolates & $316.67 \pm 64.55$ & $113.54 \pm 27.06^{*}$ & $143.75 \pm 36.97^{*}$ \\
\hline
\end{tabular}

MICs were determined using serial dilution method according to the procedures National Committee for Clinical Laboratory Standards. * indicates significant difference from rosuvastatin group. \# indicates significant difference from atorvastatin group. of the antibacterial activity of atorvastatin and simvastatin against several standard bacterial strains and clinical isolates as compared to rosuvastatin.

Statins were demonstrated to have pharmacological actions beyond their antihyperlipdimic properties including immunomodulatory, antioxidative and anticoagulant effects. A recent study indicated a direct antimicrobial effect of simvastatin and to a lesser extent fluvastatin against MSSA and MRSA [27]. Another study showed the antibacterial effect of atorvastatin and rosuvastatin in Gram + and Gram- bacteria [28]. Results of the present study extend those of previous studies to include more agents of the statins family and test these agents against a wide range of standard bacterial strains and clinical isolates.

A very recent study has reported MIC values for simvastatin against $S$. pneumoniae and $M$. catarrhalis that are similar to the ones reported in this study [29]. These MIC values reflect concentrations of statins that are higher than regular concentrations detected in human blood during statins therapy [30]. However, since multiple dose statins are known for their favorable effect on the course of bacterial infections [18-22], it is possible that statins undergoes accumulation at target human tissues upon multiple dosing, or there could a formation of relevant breakdown products in vivo. Alternatively, statins could aid the action of other antibacterial agent during the treatment of infections in human through their reported pleiotropic actions [31-33].

Statins induce their antihyperlipdimic, via inhibition of HMG-CoA reductase. In bacterial cells, HMG-CoA reductase is essential, where it is required for the biosynthesis of isoprenes [34]. However, bacterial HMG-CoA reductase is of a different structural class with an affinity for statins that is 10000 times weaker than the enzyme found in eukaryotes [34]. Thus, it is unlikely that antibacterial activity of statins can be attributed to the known mechanism of action (i.e. inhibition of HMGCoA reductase). Other possible mechanisms could be related to the pleiotropic properties of statins. For example, multiple statins including atorvastatin and simvastatin, were shown to be cytotoxic, to suppress cells growth, and to promote apoptosis [31-33]. It is possible that the currently reported antibacterial activity of statins is related to such effects.

Results of the current study showed the superiority of the antibacterial effcets of atorvastatin or simvastatin to that of rosuvastatin. Previous studies have reported distinct effects, other than the antibacterial activity, for atorvastatin and simvastatin, compared to other members of statins [35,36]. Additionally, our results show that atrovastatin was superior to simvastatin against VSE and VRE clinical isolates. These distinct effects could also be related to the differences in chemical structure 
among statins. For example, simvastatin is naturally product of fungal fermentation, whereas atorvastatin is a chemically synthesized derivative. Additionally, satins differ in their lipids affinity, thus, they could have different intrinsic activities. However, these points need more study, and could be a matter of future work.

\section{Conclusion}

In summary, results of the current study raise the possibility of a potentially important class effect and future studies are recommended to elucidate mechanism (s) by which atorvastatin and simvastatin are inducing their antibacterial effects.

\section{Competing interests}

The authors declare that they have no competing interests.

\section{Acknowledgment}

We would like to acknowledge Jordan University of Science \& Technology, Irbid; Jordan, for the financial support (grant number 73-2006 \& 226-2009).

\section{Author details}

${ }^{1}$ Faculty of Pharmacy, Jordan University of Science \& Technology, Irbid 22110, Jordan. ${ }^{2}$ Faculty of Medicine, Jordan University of Science \& Technology, Irbid 22110, Jordan

\section{Authors' contributions}

MM carried out MIC determination studies, and participated in drafting the manuscript. NM participated in MIC determination studies, and study design, and helped in drafting the manuscript. KA participated in the design of the study, performed the statistical analysis, and drafted the manuscript. SA conceived of the study, and participated in its design and coordination and helped to draft the manuscript. ZA participated in the design of the study, prepared clinical isolates, and helped to draft the manuscript. All authors read and approved the final manuscript.

Received: 19 February 2012 Accepted: 7 May 2012

Published: 7 May 2012

\section{References}

1. Chatzizisis YS, Koskinas KC, Misirli G, Vaklavas C, Hatzitolios A, Giannoglou GD: Risk factors and drug interactions predisposing to statin-induced myopathy: implications for risk assessment, prevention and treatment. Drug Saf 2010, 33:171-187.

2. Schneck DW, Knopp RH, Ballantyne CM, McPherson R, Chitra RR, Simonson SG: Comparative effects of rosuvastatin and atorvastatin across their dose ranges in patients with hypercholesterolemia and without active arterial disease. Am J Cardiol 2003, 91:33-41.

3. Kostapanos MS, Milionis HJ, Elisaf MS: An overview of the extra-lipid effects of rosuvastatin. J Cardiovasc Pharmacol Ther 2008, 13:157-174.

4. Nissen SE, Nicholls SJ, Sipahi I, Libby P, Raichlen JS, Ballantyne CM, Davignon J, Erbel R, Fruchart JC, Tardif JC, Schoenhagen P, Crowe T, Cain V, Wolski K, Goormastic M, Tuzcu EM: Effect of very high-intensity statin therapy on regression of coronary atherosclerosis: the ASTEROID trial. JAMA 2006, 295:1556-1565.

5. Furberg CD: Natural statins and stroke risk. Circulation 1999, 99:185-188.

6. Ridker PM, Danielson E, Fonseca FA, Genest J, Gotto AM Jr, Kastelein JJ, Koenig W, Libby P, Lorenzatti AJ, MacFadyen JG, Nordestgaard BG, Shepherd J, Willerson JT, Glynn RJ: Rosuvastatin to prevent vascular events in men and women with elevated C-reactive protein. $N$ Engl J Med 2008, 359:2195-2207.

7. Viasus D, Garcia-Vidal C, Gudiol F, Carratala J: Statins for communityacquired pneumonia: current state of the science. Eur J Clin Microbiol Infect Dis 2010, 29:143-152

8. Bielinska A, Gluszko P: Statins-are they potentially useful in rheumatology? Pol Arch Med Wewn 2007, 117:420-425.
9. Undas A, Brummel-Ziedins KE, Mann KG: Statins and blood coagulation. Arterioscler Thromb Vasc Biol 2005, 25:287-294.

10. Novack V, Eisinger M, Frenkel A, Terblanche M, Adhikari NK, Douvdevani A, Amichay $D$, Almog $Y$ : The effects of statin therapy on inflammatory cytokines in patients with bacterial infections: a randomized double-blind placebo controlled clinical trial. Intensive Care Med 2009, 35:1255-1260.

11. Liao JK, Laufs U: Pleiotropic effects of statins. Annu Rev Pharmacol Toxicol 2005, 45:89-118.

12. Terblanche M, Almog Y, Rosenson RS, Smith TS, Hackam DG: Statins and sepsis: multiple modifications at multiple levels. Lancet Infect Dis 2007, 7:358-368.

13. Merx MW, Liehn EA, Janssens U, Lutticken R, Schrader J, Hanrath P, Weber C: HMG-CoA reductase inhibitor simvastatin profoundly improves survival in a murine model of sepsis. Circulation 2004, 109:2560-2565.

14. Merx MW, Liehn EA, Graf J, van de Sandt A, Schaltenbrand M, Schrader J, Hanrath $P$, Weber C: Statin treatment after onset of sepsis in a murine model improves survival. Circulation 2005, 112:117-124.

15. Chaudhry MZ, Wang JH, Blankson S, Redmond HP: Statin (cerivastatin) protects mice against sepsis-related death via reduced proinflammatory cytokines and enhanced bacterial clearance. Surg Infect (Larchmt) 2008, 9:183-194.

16. Souza Neto JL, Araujo Filho I, Rego AC, Dominici VA, Azevedo IM, Egito ES, Brandao-Neto J, Medeiros AC: Effects of simvastatin in abdominal sepsis in rats. Acta Cir Bras 2006, 21(Suppl 4):8-12.

17. Chen $\mathrm{CH}$, Lee RP, Wu WT, Liao KW, Hsu N, Hsu BG: Fluvastatin ameliorates endotoxin induced multiple organ failure in conscious rats. Resuscitation 2007, 74:166-174.

18. Hackam DG, Mamdani M, Li P, Redelmeier DA: Statins and sepsis in patients with cardiovascular disease: a population-based cohort analysis. Lancet 2006, 367:413-418.

19. Almog $Y$, Shefer A, Novack V, Maimon N, Barski L, Eizinger M, Friger M, Zeller $\mathrm{L}$, Danon A: Prior statin therapy is associated with a decreased rate of severe sepsis. Circulation 2004, 110:880-885.

20. Liappis AP, Kan VL, Rochester CG, Simon GL: The effect of statins on mortality in patients with bacteremia. Clin Infect Dis 2001, 33:1352-1357.

21. Thomsen RW, Hundborg HH, Johnsen SP, Pedersen L, Sorensen HT, Schonheyder $\mathrm{HC}$, Lervang $\mathrm{HH}$ : Statin use and mortality within 180 days after bacteremia: a population-based cohort study. Crit Care Med 2006, 34:1080-1086.

22. Kruger P, Fitzsimmons K, Cook D, Jones M, Nimmo G: Statin therapy is associated with fewer deaths in patients with bacteraemia. Intensive Care Med 2006, 32:75-79.

23. Sun HY, Singh N: Antimicrobial and immunomodulatory attributes of statins: relevance in solid-organ transplant recipients. Clin Infect Dis 2009, 48:745-755.

24. Tleyjeh IM, Kashour T, Hakim FA, Zimmerman VA, Erwin PJ, Sutton AJ, Ibrahim T: Statins for the prevention and treatment of infections: a systematic review and meta-analysis. Arch Intern Med 2009, 169:1658-1667.

25. Clinical and Laboratory Standards Institute (CLSI): Performance standards for antimicrobial susceptibility testing. M100-S20. Villanova, PA:; 2010. Available from: [http://www.clsi.org/source/orders/free/m100- s20.pdf " www.clsi.org/ source/orders/free/m100-s20.pdf]. Accessed 14 September 2011. 2010.

26. CLSI: Methods for dilution antimicrobial susceptibility test for bacteria that grow aerobically. Approved standard. Eighthth edition. Villanova, PA:; 2009. Available from [http://www.clsi.org/source/orders/free/m07-a8.pdf]. Accessed 14 September 2011. 2009.

27. Jerwood S, Cohen J: Unexpected antimicrobial effect of statins. J Antimicrob Chemother 2008, 61:362-364.

28. Welsh AM, Kruger P, Faoagali J: Antimicrobial action of atorvastatin and rosuvastatin. Pathology 2009, 41:689-691.

29. Bergman P, Linde C, Putsep K, Pohanka A, Normark S, Henriques-Normark B, Andersson J, Bjorkhem-Bergman L: Studies on the antibacterial effects of statins-in vitro and in vivo. PLOS One 2011, 6:e24394.

30. Bjorkhem-Bergman L, Lindh JD, Bergman P: What is a relevant statin concentration in cell experiments claiming pleiotropic effects? $\mathrm{Br} J \mathrm{Clin}$ Pharmacol 2011, 72:164-165.

31. Yamazaki H, Suzuki M, Aoki T, Morikawa S, Maejima T, Sato F, Sawanobori K, Kitahara M, Kodama T, Saito Y: Influence of 3-hydroxy-3-methylglutaryl coenzyme $A$ reductase inhibitors on ubiquinone levels in rat skeletal muscle and heart: relationship to cytotoxicity and inhibitory activity for cholesterol synthesis in human skeletal muscle cells. J Atheroscler Thromb 2006, 13:295-307.

32. Muck AO, Seeger H, Wallwiener D: Class-specific pro-apoptotic effect of statins on human vascular endothelial cells. Z Kardiol 2004, 93:398-402. 
33. Tapia-Perez JH, Kirches E, Mawrin C, Firsching R, Schneider T: Cytotoxic effect of different statins and thiazolidinediones on malignant glioma cells. Cancer Chemother Pharmacol 2011, 67:1193-1201.

34. Friesen JA, Rodwell VW: The 3-hydroxy-3-methylglutaryl coenzyme-A (HMG-CoA) reductases. Genome Biol 2004, 5:248.

35. Tesfamariam B, Frohlich BH, Gregg RE: Differential effects of pravastatin, simvastatin, and atorvastatin on $\mathrm{Ca} 2+$ release and vascular reactivity. $J$ Cardiovasc Pharmacol 1999, 34:95-101.

36. Ishikawa M, Okajima F, Inoue N, Motomura K, Kato T, Takahashi A, Oikawa S, Yamada N, Shimano H: Distinct effects of pravastatin, atorvastatin, and simvastatin on insulin secretion from a beta-cell line, MIN6 cells. J Atheroscler Thromb 2006, 13:329-335.

doi:10.1186/1476-0711-11-13

Cite this article as: Masadeh et al: Antibacterial activity of statins: a

comparative study of Atorvastatin, Simvastatin, and Rosuvastatin. Annals of Clinical Microbiology and Antimicrobials 2012 11:13.

\section{Submit your next manuscript to BioMed Central and take full advantage of:}

- Convenient online submission

- Thorough peer review

- No space constraints or color figure charges

- Immediate publication on acceptance

- Inclusion in PubMed, CAS, Scopus and Google Scholar

- Research which is freely available for redistribution 